\title{
A INTERTEXTUALIDADE ENTRE A POLÍTICA DE EDUCAÇÃO AMBIENTAL E AS POLÍTICAS PÚBLICAS DE EDUCAÇÃO BÁSICA
}

\author{
Tereza Joelma Barbosa Almeida ${ }^{1}$ \\ Ana Sueli Teixeira de Pinho ${ }^{2}$
}

\begin{abstract}
Resumo: $\mathrm{O}$ artigo A Intertextualidade entre a Política de Educação Ambiental e as Políticas Públicas de Educação Básica tem por objetivo estabelecer relações entre leis e outros dispositivos legais que regulamentam e orientam a Política de Educação Ambiental e as Políticas Públicas de Educação Básica. A perspectiva metodológica adotada configurou-se como uma pesquisa bibliográfica e permitiu a constatação de um certo distanciamento entre as metas estabelecidas para as duas políticas que nem sempre são convergentes.
\end{abstract}

Palavras-chave: Educação Ambiental. Políticas de Educação Básica. Meio Ambiente.

\section{THE INTERTEXTUALITY BETWEEN ENVIRONMENTAL EDUCATION POLICY AND PUBLIC POLICIES OF BASIC EDUCATION}

\begin{abstract}
The article Intertextuality between the Environmental Education Policy and the Public Policies of Basic Education, aims to establish relations between laws and other legal provisions that regulate and guide the Environmental Education Policy and Public Policies of Basic Education in Bahia. The methodological perspective adopted was set up as a bibliographical research and allowed the finding of a certain distance between the goals established for the two policies that are not always convergent.
\end{abstract}

Keywords: Environmental Education. Basic Education Policies. Environment.

\footnotetext{
${ }^{1}$ Licenciada em Ciências Biológicas pela Faculdade Jorge Amado - Salvador - BA. Especialista em Educação Ambiental pela UNINTER. Mestranda no Programa de Pós-Graduação em Planejamento Ambiental pela Universidade Católica do Salvador - UCSal. Professora da Rede Estadual de Ensino da Bahia. Membro do Grupo de Pesquisa Docência e Gestão em Educação - GRUDGE.

${ }^{2}$ Doutora em Educação e Contemporaneidade pela Universidade do Estado da Bahia. Professora da Universidade Católica do Salvador (Programa de Pós-Graduação em Planejamento Ambiental e Curso Graduação em Pedagogia). Assessora Acadêmica no Instituto Anísio Teixeira - IAT. Líder do Grupo de Pesquisa Docência e Gestão em Educação - GRUDGE e membro do Grupo de Pesquisa Autobiografia, Formação e História Oral - GRAFHO.
} 


\section{Introdução}

Este artigo intitulado $A$ Intertextualidade entre a Política Nacional de Educação Ambiental e as Políticas Públicas de Educação Básica tem por objetivo estabelecer relações entre leis e outros dispositivos legais que regulamentam e orientam a Política Nacional de Educação Ambiental e a Política Pública de Educação Básica na Bahia.

Contemporaneamente, a preocupação com o meio ambiente tem estado presente na vida de grande parte da população em vários países do mundo. A mídia tem se encarregado de divulgar, cotidianamente, grandes catástrofes ambientais, naturais ou provocadas pela atividade do ser humano. O modelo atual de desenvolvimento econômico, baseado na lógica capitalista, tem contribuído para o agravamento dessa situação, culminando com a degradação ambiental. Diante desse cenário, verifica-se uma urgente necessidade de redução do consumo pela humanidade e criação de alternativas para o cuidado com o meio ambiente, tendo em vista a sua conservação e preservação.

A partir dessa compreensão sobre a necessidade de produção do conhecimento sobre o ambiente natural, Boff $(2010$, p. 71$)$ denuncia que “estamos cansados de meio ambiente. Precisamos do ambiente inteiro, da comunidade terrenal. Quer dizer: não é suficiente cuidar da natureza. Urge cuidar do ser humano, parte e parcela essencial da natureza". No entanto, vários autores apontam que isso só será possível por meio da educação. Como destaca Freire (2000, p. 31): "Se a educação sozinha não transforma a sociedade, sem ela tampouco a sociedade muda"

É esse reconhecimento que justifica o papel da educação no processo de transformação do conhecimento e da relação do ser humano com a natureza, pois é ela quem promove a construção de um saber ético fundado na consciência de que o humano é, ao mesmo tempo, indivíduo, parte da sociedade, parte da espécie (MORIN, 2011).

Considerando a necessidade de definição de Políticas Públicas para a Educação Básica que considerem as Políticas de Educação Ambiental é que se justifica a relevância desta pesquisa que propõe a análise cruzada das leis e de 
outros dispositivos legais em torno dessas temáticas. Assim, o texto está organizado da seguinte forma: breve histórico da Política de Educação Ambiental; relação intertextual entre a Política Nacional de Educação Ambiental e as Políticas Públicas de Educação Básica; análise de leis e outros dispositivos legais que orientam a Educação Básica; metodologia; resultados e discussão; considerações finais e referências.

\section{Breve Histórico da Política de Educação Ambiental}

Historicamente, as preocupações com as questões ambientais vêm sendo alvo de alerta da sociedade, na literatura, vale destacar um marco no que se refere às agressões do homem para com o meio ambiente e a vida no planeta, a obra literária de Rachel Carson.

Em 1962, Rachel Carson, bióloga e escritora, foi responsável pela maior revolução ecológica dos Estados Unidos e do mundo, quando lançou o livro Primavera Silenciosa, em outubro de 1962. Nesta obra literária, a autora denuncia a insensatez humana diante da natureza, bem como a incapacidade de prever e prevenir riscos futuros para com o planeta (CARSON, 1962).

Mesmo considerando a importância das denúncias feitas pela bióloga, os primeiros registros da utilização do termo Educação Ambiental surgiram, de fato, pela primeira vez em 1965, com o uso da expressão environmental education (educação ambiental), durante a Conferência de Educação da Universidade de Keele, na Grã-Bretanha. No entanto, os rumos da Educação Ambiental começaram a ser realmente definidos a partir da Conferência das Nações Unidas sobre o Meio Ambiente Humano, realizada em Estocolmo, em 1972, onde se atribuiu a inserção da temática da Educação Ambiental na agenda internacional.

Em 1975, lançou-se em Belgrado (na então Iugoslávia) o Programa Internacional de Educação Ambiental, no qual foram definidos os princípios e orientações para o futuro. A Carta de Belgrado que considera, como destinatário principal da Educação Ambiental, o público em geral, sendo esta formal ou não-formal, estabelece que: 
[...] a meta da Educação Ambiental é formar uma população mundial consciente e preocupada com o meio ambiente e com os problemas associados, e que tenha conhecimento, aptidão, atitude, motivação e compromisso para trabalhar individual e coletivamente na busca de soluções para os problemas existentes e para prevenir novos (Carta de Belgrado, 1975).

No ano de 1977, foi realizada a Conferência Intergovernamental sobre Educação Ambiental, organizada pela Unesco em cooperação com o Pnuma, na cidade de Tbilisi, na qual a educação ambiental foi introduzida como estratégia para conduzir a sustentabilidade ambiental e social do planeta. Deste encontro saíram as definições, os objetivos, os princípios e as estratégias para a Educação Ambiental que até hoje são adotados em todo o mundo (BRASIL, Ministério do Meio Ambiente, 2016).

No Brasil, foi instituída a Política Nacional do Meio Ambiente, Lei no

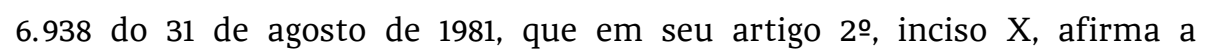
necessidade de promover a "Educação Ambiental a todos os níveis de ensino, inclusive a educação da comunidade, objetivando capacitá-la para participação ativa na defesa do meio ambiente". Assim, a Educação Ambiental nasceu como um princípio e um instrumento da política ambiental.

Em 1987, o Ministério da Educação e Cultura - MEC aprovou o Parecer 226/87 do conselheiro Arnaldo Niskier, que reafirmou a necessidade de inclusão da Educação Ambiental nos currículos escolares de 1o e 2 o Graus (BRASIL/MEC, 2016).

A Constituição Federal, de 1988, reconheceu o direito constitucional de todos os cidadãos brasileiros à Educação Ambiental e atribuiu ao Estado o dever de "promover a Educação Ambiental em todos os níveis de ensino e a conscientização pública para a preservação do meio ambiente” (Art. 225, §1ํ, inciso VI).

Em 1992, durante a Conferência das Nações Unidas sobre Meio Ambiente e Desenvolvimento, realizada no Rio de Janeiro, o conceito de desenvolvimento sustentável foi definitivamente incorporado como um princípio orientador de ações. Foi, então, elaborada a Agenda 21, que 
representa um compromisso das nações de agir em cooperação e harmonia na busca do desenvolvimento sustentável.

Em 1999, foi sancionada a Lei no 9.795/99 que instituiu a Política Nacional de Educação Ambiental (PNEA), que veio reforçar e qualificar o direito de todos à Educação Ambiental, indicando seus princípios e objetivos, os atores e instâncias responsáveis por sua implementação, nos âmbitos formal e não-formal, e as suas principais linhas de ação.

De acordo com o Artigo 1을 da respectiva lei:

Entendem-se por educação ambiental os processos por meio dos quais o indivíduo e a coletividade constroem valores sociais, conhecimentos, habilidades, atitudes e competências voltadas para a conservação do meio ambiente, bem de uso comum do povo, essencial à sadia qualidade de vida e sua sustentabilidade. (BRASIL/PNEA, 1999).

Sobre a formação inicial de professores, a Lei 9.795/99 preceitua, em seu artigo 11, que "a dimensão ambiental deve constar dos currículos de formação de professores, em todos os níveis e em todas as disciplinas". Para tanto, a Lei faculta a inserção de disciplina específica de Educação Ambiental apenas para os "cursos de pós-graduação, extensão e nas áreas voltadas ao aspecto metodológico da Educação Ambiental, quando se fizer necessário" (Art. 10, $\S 2^{\circ}$ ).

Assim, pretende-se, de acordo com a lei que estabelece a PNEA, a inserção da Educação Ambiental nas instituições de ensino para a formação de docentes e discentes, com o ensino de valores éticos, senso crítico e reflexivo sobre as questões ambientais, na perspectiva de uma sustentabilidade socioambiental.

O Decreto no 4.281, de 25/06/02, regulamentou a Lei no 9.795/99, com as definições de competências, atribuições e mecanismos para a PNEA e criou o Órgão Gestor, responsável pela coordenação da PNEA, constituído pela Diretoria de Educação Ambiental do Ministério do Meio Ambiente (DEA/MMA), e pela Coordenação-Geral de Educação Ambiental do Ministério da Educação (BRASIL/ MEC/CGEA, 2002). 
Nessas transformações sociais, as políticas públicas e educacionais vão se organizando e se estruturando, criando e implementando leis que contemplem a urgente necessidade do tratamento da Educação Ambiental nos mais diversos contextos sociais e, em especial, no âmbito escolar.

Em julho de 2010, a Resolução CNE/CEB 04/2010, no seu artigo 16, considera que "Leis específicas, que complementam a LDB, determinam que sejam incluídos componentes não disciplinares, como temas relativos [...] ao meio ambiente". Essa deliberação é retomada com a resolução CNE/CEB no 07/2010 que estabelece as Diretrizes Curriculares Nacionais para o Ensino Fundamental de 9 (nove) anos (BRASIL/ CNE/CEB, 2010).

A Resolução no 2, de 30 de janeiro de 2012, que define as Diretrizes Curriculares Nacionais para o Ensino Médio, no seu artigo 10, estabelece que em decorrência de legislação específica, são obrigatórios: “II - Com tratamento transversal e integradamente, permeando todo o currículo, no âmbito dos demais componentes curriculares: [...] Educação Ambiental”. (BRASIL/PNEA, 1999).

A Lei no 12.608, de 10 de abril de 2012, que instituiu a Política Nacional de Proteção e Defesa Civil - PNPDEC e, dentre outras coisas, altera no seu artigo 29 o parágrafo 7ํ do artigo 26 da LDB no 9.394/1996, cujo caput estabelece: "os currículos do ensino fundamental e médio devem incluir os princípios da proteção e defesa civil e a educação ambiental de forma integrada aos conteúdos obrigatórios". Em 2016, este parágrafo sofreu nova alteração com a Medida Provisória no 746, ficando com a seguinte redação “a Base Nacional Comum Curricular disporá sobre os temas transversais que poderão ser incluídos nos currículos de que trata o caput”.

Em 15 de junho de 2012, foi homologada a Resolução CNE/CP no 2, que estabelece as Diretrizes Curriculares Nacionais para a Educação Ambiental, que "reconhece o papel transformador e emancipatório da Educação Ambiental diante dos problemas ambientais vividos em tempos atuais". (BRASIL/ CNE, 2012).

Assim sendo, de acordo com o Artigo 2o da Resolução 02 do CNE, a Educação Ambiental deve ser uma dimensão da educação, uma atividade intencional da prática social, que deve imprimir ao desenvolvimento 
individual um caráter social em sua relação com a natureza e com os outros seres humanos, visando a potencializar essa atividade humana com a finalidade de torná-la plena de prática social e de ética ambiental.

\section{A Intertextualidade entre a Política de Educação Ambiental e Política Pública de Educação Básica}

A Coordenação-Geral de Educação Ambiental (CGE), em sua condição de integrante do Órgão Gestor da Política Nacional de Educação Ambiental, encaminhou ao Conselho Nacional de Educação (CNE) as Diretrizes Curriculares Nacionais relacionadas à Educação Ambiental que, conforme exigência legal, devem estar presentes em todos os níveis e modalidades de ensino, sugerindo também a inserção da dimensão ambiental nos diferentes cursos de Ensino Superior. No curso de pedagogia e nas diferentes licenciaturas (formação inicial de professores), a Educação Ambiental deve se constituir como atividade curricular, disciplina ou projeto interdisciplinar, capaz de acrescentar a tal formação, não apenas os conteúdos dessa temática, mas a relação dela com as diversas áreas do conhecimento, além de promover uma formação crítica que fomente a adoção de uma postura ética, política e o papel social dos docentes para a construção do projeto capaz de promover o exercício da cidadania. (MEC/CNE/SECAD, 2007).

Importante deixar claro que, para a Educação Básica, não se pretende a inclusão da temática transversal da Educação Ambiental como disciplina curricular (até mesmo porque o Artigo 10, §1ํㅡㄹ da Lei 9.795/99 não autoriza este tipo de inserção). Ao contrário, o que se pretende é fortalecer a sua característica interdisciplinar, para que a Educação Ambiental possa continuar perpassando e avançando nas modalidades educativas e ramos científicos - mantendo um vínculo comum e verdadeiramente conexo com elas, respeitando-se sempre a liberdade da comunidade escolar para construir o conteúdo pedagógico a ser desenvolvido. (MEC/CNE, 2010).

A partir da análise do Plano Nacional de Educação - PNE (2014-2024), foi possível constatar que este tão importante dispositivo legal ignora a 
Política Nacional de Educação Ambiental (PNEA). Não há referência textual sobre a formação profissional do professor para a Educação Ambiental. A meta 13 que trata da qualidade da Educação Superior e ampliação da quantidade de mestres e doutores nesse nível de ensino estabelece na estratégia 13.4 a necessidade de:

\begin{abstract}
promover a melhoria da qualidade dos cursos de pedagogia e licenciaturas, por meio da aplicação de instrumento próprio de avaliação aprovado pela Comissão Nacional de Avaliação da Educação Superior CONAES, integrando-os às demandas e necessidades das redes de educação básica, de modo a permitir aos graduandos a aquisição das qualificações necessárias a conduzir o processo pedagógico de seus futuros alunos(as), combinando formação geral e específica com a prática didática, além da educação para as relações étnico-raciais, a diversidade e as necessidades das pessoas com deficiência (BRASIL, PNE, 2016).
\end{abstract}

E na estratégia 14.14, define a necessidade de:

estimular a pesquisa científica e de inovação e promover a formação de recursos humanos que valorize a diversidade regional e a biodiversidade da região amazônica e do cerrado, bem como a gestão de recursos hídricos no semiárido para mitigação dos efeitos da seca e geração de emprego e renda na região (BRASIL, PNE, 2016).

No Art. $2 \stackrel{\circ}{\circ}$, que trata das diretrizes do PNE, inciso X, define a necessidade de - promoção dos princípios do respeito aos direitos humanos, à diversidade e à sustentabilidade socioambiental (PNE, 2014-2024). Essa mesma redação é observada no Plano Estadual de Educação da Bahia, sem nenhuma alteração. Ainda em se tratando do Plano Nacional de Educação (2014-2024), identifica-se que este se encontra estruturado em grupos, cujas metas e estratégias estão organizadas da seguinte forma:

O primeiro grupo são metas estruturantes para a garantia do direito a educação básica com qualidade, e que assim promovam a garantia do acesso, à universalização do 
ensino obrigatório e à ampliação das oportunidades educacionais. Um segundo grupo de metas diz respeito, especificamente, à redução das desigualdades e à valorização da diversidade, caminhos imprescindíveis para a equidade. O terceiro bloco de metas trata da valorização dos profissionais da educação, considerada estratégica para que as metas anteriores sejam atingidas, e o quarto grupo de metas refere-se ao ensino superior, onde pretende-se elevar a taxa de matrícula, bem como, elevar a qualidade da educação superior e ampliar a proporção de mestres e doutores do corpo docente em efetivo exercício. (BRASIL, MEC, 2016)

Vale ressaltar que o Plano Estadual de Educação da Bahia segue o que vigora na redação do PNE, e nessa intertextualidade observada entre as políticas nacionais e estaduais de educação, nota-se que não há metas definidas para o tratamento da Educação Ambiental no âmbito da Política Pública aqui referida.

\section{Leis e Documentos que Orientam a Política de Educação Básica}

Em se tratando da LDB (Lei de Diretrizes e Bases da Educação) Lei no 9.394, de 20/12/96 - Diretrizes e Bases da Educação Nacional, observa-se que existem poucas menções à Educação Ambiental. A referência no âmbito da lei ocorre no artigo 32, inciso II, segundo o qual se exige, para o Ensino Fundamental, a "compreensão ambiental natural e social do sistema político, da tecnologia, das artes e dos valores em que se fundamenta a sociedade". O artigo 36 determina que os currículos do ensino fundamental e médio tenham uma base em comum a ser complementada por uma parte diversificada exigida pelas características regionais e locais da sociedade. Nesse sentido prevê, em seu § 1 - os currículos a que se refere o caput devem abranger, obrigatoriamente, o conhecimento do mundo físico e natural e da realidade social e política, especialmente no Brasil (LDB, 1996).

Em 1997 e 1998, respectivamente, os Parâmetros Curriculares Nacionais (PCNs) referentes aos primeiros e segundos ciclos e os PCNs relativos ao terceiro e quarto ciclos do Ensino Fundamental foram aprovados 
pelo Conselho Nacional de Educação. Os PCNs se constituíram subsídios para apoiar a escola na elaboração do seu projeto educativo, inserindo procedimentos, atitudes e valores no convívio escolar, bem como a necessidade de tratar de alguns temas sociais urgentes, de abrangência nacional, denominados como temas transversais: meio ambiente, ética, pluralidade cultural, orientação sexual, trabalho e consumo, com possibilidade de as escolas e/ou comunidades elegerem outros de importância relevante para sua realidade (BRASIL, PCN/MEC, 1997).

No referido parágrafo da LDB, ao propor a ideia de conhecimento e compreensão do mundo físico e natural, restringe-se à ideia de fatores físicos, biológicos e socioeconômicos, este último ao referenciar-se aos valores em que se fundamenta a sociedade, atualmente capitalista. Ideia essa consolidada como tema transversal, meio ambiente, pelos Parâmetros Curriculares Nacionais. A Política Nacional de Educação Ambiental traz uma ideia com um conceito mais amplo, ao propor o tema Educação Ambiental, pois, para além da compreensão e conhecimento do mundo físico e natural, propõe o ensino de valores que venham a propiciar mudança comportamental do indivíduo, de cuidado e proteção desse ambiente. Não basta apenas conhecer e compreender, é necessário que a educação pública contribua para mudanças atitudinais nos discentes, alicerçados no ensino de valores éticos de cuidado do planeta.

A Base Nacional Comum Curricular (BNCC), que em 2016 teve publicada sua segunda versão e que ainda aguarda sua regulamentação pelo $\mathrm{CNE}$, se constitui numa exigência colocada para o sistema educacional brasileiro pela Lei de Diretrizes e Bases da Educação Nacional (Brasil, 1996; 2013), pelas Diretrizes Curriculares Nacionais da Educação Básica (Brasil, 2009) e pelo Plano Nacional de Educação (Brasil, 2014), e deve se configurar como um avanço na construção da qualidade da educação. Para o Ministério da Educação, o que deve nortear um projeto de nação é a formação humana integral e uma educação de qualidade social. (BRASIL/ Base Nacional Comum Curricular, 2016).

De acordo com a BNCC (2016), a aprendizagem e desenvolvimento são processos contínuos que se referem a mudanças que se dão ao longo da 
vida, integrando aspectos físicos, emocionais, afetivos, sociais e cognitivos. Ao tratar do direito de aprender e de se desenvolver, busca-se colocar em perspectiva as oportunidades de desenvolvimento do/a estudante e os meios para garantir-lhe a formação comum, imprescindível ao exercício da cidadania. Esses direitos se explicitam em relação aos princípios éticos, políticos e estéticos, nos quais se fundamentam as Diretrizes Curriculares Nacionais, e que devem orientar uma Educação Básica que vise à formação humana integral, à construção de uma sociedade mais justa, na qual todas as formas de discriminação, preconceito e exclusão sejam combatidas.

Os temas especiais propostos pela BNCC: economia, educação financeira e sustentabilidade; culturas indígenas e africanas; culturas digitais e computação; direitos humanos e cidadania; educação ambiental, são temas que dizem respeito a questões que atravessam as experiências dos sujeitos em seus contextos de vida e atuação e que, portanto, intervêm em seus processos de construção de identidade e no modo como interagem com outros sujeitos e com o ambiente, posicionando-se ética e criticamente sobre e no mundo. Trata-se, portanto, de temas sociais contemporâneos que contemplam, para além da dimensão cognitiva, as dimensões política, ética e estética da formação dos sujeitos, na perspectiva de uma educação humana integral. (BRASIL/Base Nacional Comum Curricular, 2016).

A BNCC (2016) ainda destaca que, ao eleger a educação ambiental como tema especial, almeja-se articular direitos e objetivos de aprendizagem em torno das questões socioambientais, de tal forma que os currículos escolares sejam capazes de debater a continuidade da vida de todas as espécies, inclusive a humana, no planeta terra.

Assim, a educação ambiental vai sendo inserida no contexto escolar para formação do discente, através do ensino não só de conteúdos disciplinares, mas a educação de valores éticos, senso crítico e reflexivo sobre as questões ambientais, na perspectiva de uma sustentabilidade socioambiental.

Nesse sentido, a Secretaria da Educação do Estado da Bahia propõe o programa ProEASE (Programa de Educação Ambiental do Estado da Bahia) em consonância ao que se estabelece na Constituição Federal e na Política 
Nacional de Educação Ambiental, através do qual tem por objetivo fortalecer e orientar a educação ambiental nos sistemas de ensino, com propostas pedagógicas que venham a propiciar uma mudança na relação homemnatureza, no ensino de valores e promoção da cidadania.

Ainda desenvolve o Projeto Juventude em Ação (JA): Construindo Agenda 21 nas escolas, que foi concebido como uma estratégia inovadora de mobilização e capacitação de jovens e professores da Rede Estadual de Ensino, com uma metodologia participativa e democrática, tendo em vista a interdisciplinaridade e a complexidade da educação ambiental, estendendo-se o conhecimento a toda a comunidade do entorno escolar. O objetivo geral do respectivo projeto visa a promover a formação de Comissões de Meio Ambiente e Qualidade de Vida - COM-VIDA para a elaboração da Agenda 21, dentro das comunidades escolares da Rede Estadual de Ensino, com base em valores voltados para a sustentabilidade em suas múltiplas dimensões. A estratégia metodológica do projeto incentiva o protagonismo juvenil, estabelecendo ações e metas a serem realizadas através de um diagnóstico participativo da realidade socioambiental da escola, promovendo a inclusão da Educação Ambiental de forma transversal e interdisciplinar (SEC-BA, 2016).

A partir dessas iniciativas, as Políticas Estaduais em Educação da Bahia buscam a efetivação do que se estabelece no texto da Lei da Política Nacional de Educação Ambiental.

\section{Material e Método}

Este estudo constitui-se em uma pesquisa bibliográfica motivada pela coleta de material bibliográfico para elaboração do projeto de dissertação do mestrado, no qual percebemos a necessidade da análise crítica comparativa entre os textos que constituem as políticas públicas educacionais, leis e documentos que orientam a Educação Básica, à luz do tema Educação Ambiental. Considerou-se o período inicial da abordagem da educação ambiental, identificado em 1965, assim como os principais marcos e acontecimentos referentes às questões ambientais nos anos seguintes e as leis 
e documentos instituídos durante este período até o presente momento que tratam desta temática e da Política Pública de Educação Básica na Bahia.

Realizou-se uma consulta a artigos científicos, bem como leis e documentos que orientam a Educação Básica, selecionados através de busca no banco de dados do Scielo, sites do Ministério de Educação e Ministério de Meio Ambiente, Secretaria de Educação do Estado da Bahia, realizada entre outubro e dezembro de 2016.

Os critérios adotados para a inclusão dos artigos consideraram as categorias conceituais Educação Ambiental, meio ambiente e as Políticas Públicas voltadas para a Educação Nacional e Estadual, bem como outras leis e documentos (LDB, PCN, BNCC) pertinentes para a análise intertextual.

A partir da seleção do material bibliográfico, foram realizadas leituras comparativas, cruzando informações relevantes, que pudessem subsidiar a compreensão da organização política da educação na perspectiva da Educação Ambiental.

A análise e interpretação dos dados deram-se pela identificação dos pontos convergentes e divergentes entre a relação textual estabelecida nas respectivas leis e documentos educacionais.

\section{Resultados e Discussão}

A intertextualidade, percebida na análise das leis e outros dispositivos legais que orientam a prática pedagógica, nos revela que não estamos politicamente organizados, na perspectiva da educação ambiental, uma vez que se observa um distanciamento entre os termos e conceitos trazidos nos documentos que orientam a educação ambiental e as leis das políticas em educação. Esta constatação permitiu identificar uma pouca valoração e priorização das questões sobre educação ambiental, determinadas por uma Política Nacional de Educação Ambiental.

Portanto, a Política Nacional de Educação Ambiental (PNEA) não se insere textualmente com sua devida valoração e relevância no Plano Nacional de Educação (BRASIL, MEC/PNE, 2014-2024) tampouco é referida no Plano Estadual de Educação da Bahia (BAHIA, SEC/PEE-BA, 2016-2026). No entanto, 
o Programa de Educação Ambiental do Sistema Educacional da Bahia ProEASE, que foi revisado e encontra-se na sua segunda edição (BAHIA, SEC2015), atende ao proposto pelo texto da lei da Política Nacional de Educação Ambiental, na medida em que prevê a implementação da Educação Ambiental em todas as etapas da Educação Básica e na formação dos professores. Vale ressaltar ainda nessa atual conjuntura social, política, econômica e educacional, a necessidade de nos organizarmos politicamente em prol de uma melhor efetivação da Política Nacional de Educação Ambiental, para sua implementação, em todos os níveis e modalidades de ensino, bem como, pensar a inserção da educação ambiental enquanto disciplina no nível superior, para formação do profissional pedagogo e licenciado que irá atuar nas instituições educacionais.

Com relação às metas do Plano Nacional de Educação analisado, identifica-se que na meta 13 que trata da elevação da qualidade da educação superior e ampliação da proporção de mestres e doutores do corpo docente em efetivo exercício no conjunto do sistema de educação superior, a estratégia 13.4 não inclui a educação ambiental enquanto conhecimento fundamental para formação dos profissionais em pedagogia e licenciatura.

Na meta 14 que trata da elevação gradual do número de matrículas na pós-graduação stricto sensu, aponta na estratégia 14.4, a ausência da educação ambiental, vez que destaca apenas a preocupação em estimular a pesquisa científica e de inovação para formar recursos humanos que valorizem a diversidade e biodiversidade mundial, no texto da estratégia deveria também estar inserida a necessidade de se promover a mitigação dos efeitos antrópicos que tem gerado toda essa degradação ambiental e alterações climáticas severas.

No que se refere à LDB (Lei de Diretrizes e Bases da Educação), notase que ao propor a ideia de conhecimento e compreensão do mundo físico e natural, limita-se a ideia teórica de meio ambiente com seus aspectos físicos, biológicos e socioeconômicos, ao considerar os valores em que se fundamenta a sociedade, atualmente capitalista, sem perspectiva de mudança da relação homem-ambiente. Sabemos, pois, que não é suficiente conhecer e compreender o meio ambiente, é essencial que a educação pública contribua 
para mudanças positivas dos estudantes, tendo como base o ensino de valores éticos e de cuidado do meio ambiente.

Em se tratando da Base Nacional Comum Curricular, observa-se a inclusão da temática educação ambiental com seu devido valor e relevância para formação do estudante, considerando o texto da Política Nacional de Educação Ambiental. Importante destacar que o tema transversal proposto pelos Parâmetros Curriculares Nacionais, qual seja o meio ambiente, se encontra em processo de revisão pela Base Nacional Comum Curricular que apresenta a categoria conceitual para a Educação Básica como tema especial.

Identifica-se, na BNCC (2016), a necessidade de se promover uma educação ambiental enquanto tema especial, tendo em vista uma aprendizagem em torno das questões socioambientais, que deverão estar contempladas nos currículos escolares através do ensino, não são de conteúdos disciplinares, mas de valores éticos, senso crítico e reflexivo na perspectiva de uma sustentabilidade socioambiental.

Assim sendo, a Base Nacional Comum Curricular vem trazendo mudanças coerentes e pertinentes relacionados ao proposto na Política Nacional de Educação Ambiental, na qual a Educação Ambiental deve ser um processo de educação que forme indivíduos responsáveis e preocupados com as questões ambientais, que busquem a conservação e preservação dos recursos naturais numa visão holística que considera a complexidade desta temática nos seus aspectos econômicos, sociais, políticos, ecológicos e éticos.

Percebe-se ainda que as bases para a consolidação de uma política pública de educação ambiental vêm sendo definidas, e a Secretaria de Educação do Estado da Bahia tem buscado promover importantes e significativos avanços através de programas e projetos escolares desenvolvidos para efetivação da Política Nacional de Educação Ambiental.

\section{Considerações Finais}

Se a meta da educação ambiental é formar uma população mundial consciente e preocupada com o meio ambiente e com os problemas associados, e que tenha conhecimento, aptidão, atitude, motivação e 
compromisso para trabalhar individual e coletivamente na busca de soluções para os problemas existentes e para prevenir novos (BRASIL, MMA/ Carta de Belgrado, 1975), tal temática deveria estar contemplada como meta prioritária, com sua devida valoração e meios para sua implementação na educação formal, conforme proposto pela Política Nacional de Educação Ambiental, devendo ser componente essencial e permanente da educação nacional.

Apesar de no Brasil existir a ideia de leis que não pegam, uma lei existe para ser cumprida ou questionada (SORRENTINO, et al, 2005). Assim sendo, uma educação ambiental para o ensino de valores éticos e que promovam transformações dos sujeitos para com o meio ambiente depende de que o sistema educacional esteja politicamente organizado para atingir as metas e objetivos pretendidos pela Política Nacional de Educação Ambiental.

Gadotti (1979), no prefácio do livro Paulo Freire: Educação e Mudança, destaca que depois de Paulo Freire ninguém mais pode ignorar que a educação é um ato político. Aqueles que argumentam que o educador não pode fazer política estão defendendo uma certa política, a política da despolitização.

Fazer política é um exercício crítico e reflexivo de participação social, no qual a promoção da cidadania se efetiva quando educadores oportunizam estudantes a exercitarem seus direitos e deveres frente às questões e problemas sociais.

Nesse universo, é salutar a análise intertextual entre as leis e documentos que orientam a educação pública, a fim de compreendermos e propormos mudanças mais eficazes para a consolidação de uma Política Pública de Educação Ambiental, uma vez que em tempos atuais se presencia um planeta doente e carente de cuidados especiais.

\section{Referências}

BOFF, Leonardo. Do iceberg à arca de Noé. O nascimento de uma Ética Planetária. 2 ed. Rio de Janeiro: Mar de Ideias, 2010.

BAHIA. Secretaria de Educação do Estado da Bahia. Lei no 13.559 de 11 de maio de 2016. Aprova o Plano Estadual de Educação da Bahia e dá outras 
A INTERTEXTUALIDADE ENTRE A POLITICA DE EDUCAÇẪO AMBIENTAL E AS POLITICAS PÚBLICAS DE EDUCAÇĀOO BÁSICA

providências. Disponível em: <http://www. institucional.educacao.ba.gov.br/ Acesso em: out. de 2016.

BAHIA. Secretaria de Educação do Estado da Bahia. Programa de Educação Ambiental do Sistema Educacional da Bahia - ProEASE. 2a ed. Salvador: SEC 2015. $131 \mathrm{p}$.

BRASIL. Lei no 13.005, de 25 de junho de 2014. Aprova o Plano Nacional de Educação (PNE/2014-2024) e dá outras providências. Brasília : Câmara dos Deputados, Edições Câmara, 2014. 86 p. - (Série legislação ; n. 125). Disponível em: <http://www.planalto.gov.br/> Acesso em: out. de 2016.

BRASIL. Ministério da Educação/Secretaria de Articulação com os sistemas de ensino (MEC/SASE), 2014. Planejando a Próxima Década: Conhecendo as 20 metas do Plano Nacional de Educação. Disponível em: Disponível em: <http://www.planalto.gov.br/> Acesso em: out. de 2016.

BRASIL. Ministério do Meio Ambiente (MMA). Carta de Belgrado. Disponível em: < http:// www.mma.gov.br/ Acesso em: out. de 2016.

BRASIL. Constituição (1988). Constituição da República Federativa do Brasil. Brasília, DF: Senado, 1988.

BRASIL. Decreto 4.281, de 25.06.2002. Regulamenta a Lei n. 9.795, de 27 de abril de 1999, que institui a Política Nacional de Educação Ambiental, e dá outras providências. DOU 26.06.2002. Disponível em: <http://www.planalto.gov.br/> Acesso em: dez. de 2016.

BRASIL. Lei 6.938, de 31.08.1981. Dispõe sobre a Política Nacional do Meio Ambiente, seus fins e mecanismos de formulação e aplicação, e dá outras providências. DOU 02.09.1981. Disponível em: <http://www.planalto.gov.br/> Acesso em: nov. de 2016.

BRASIL. Lei 9.394, de 20.12.1996. Estabelece as Diretrizes e Bases da Educação Nacional. DOU 23.12.1996. Disponível em:<http://www.planalto.gov.br/> Acesso em: dez. de 2016.

BRASIL. Lei 9.795, de 27.04.1999. Dispõe sobre Educação Ambiental e institui a Política Nacional de Educação Ambiental, e dá outras providências. DOU 28.04.1999. Brasil. Lei 10.172, de 09.01.2001. Aprova o Plano Nacional de Educação, e dá outras providências. DOU 10.01.2001. Disponível em: <http://www.planalto.gov.br/> Acesso em: nov. de 2016.

BRASIL. Ministério da Educação. Secretaria da Educação Fundamental. Parâmetros Curriculares Nacionais - 1aa a 4a série. Brasília: MEC/SEF, 1997. 
BRASIL. Ministério da Educação. Secretaria da Educação Fundamental. Parâmetros Curriculares Nacionais - 5a a 8a série. Brasília: MEC/SEF, 1998.

BRASIL. Ministério da Educação. Propostas de Diretrizes da Educação Ambiental para o ensino formal - Resultado do II Encontro Nacional de representantes de EA das Secretarias Estaduais e Municipais (capitais) de Educação - 2001. Disponível em: <http://www.planalto.gov.br/> Acesso em: Nov. de 2016.

FREIRE, Paulo. Pedagogia da Indignação: cartas pedagógicas e outros escritos. São Paulo: UNESP, 2000.

GADOTTI, Moacir. Paulo Freire: Educação e mudança. 12 ed. Campinas: Paz e Terra, 1979.

MEC. Parâmetros curriculares nacionais: terceiro e quarto ciclos do ensino fundamental: introdução aos parâmetros curriculares nacionais. Brasília, 1998.

MEC. Secretaria de Educação Fundamental. Parâmetros curriculares nacionais: Apresentação dos Temas Transversais. Brasília: Ética, 2001.

MEC. Secretaria de Educação Fundamental. Parâmetros Curriculares Nacionais - terceiro e quarto ciclos: apresentação dos temas transversais. Brasília, 1998.

MMA. Ministério do Meio Ambiente. Disponível em: $<$ http://www.mma. gov.br>. Acesso em: set. de 2016.

MORIN, Edgar. Os sete saberes necessários à educação do futuro. 2 ed. São Paulo: Cortez, 2011.

PORTAL EDUCAÇÃO. $O$ Clube de Roma. Disponível em: <http://www. portaleducacao.com.br>. Acesso em: set. de 2016.

SORRENTINO, Marcos. Educação ambiental como política pública. Educação e Pesquisa, São Paulo, v. 31, n. 2, p. 285-299, maio/ago 2005.

SEC-BA. Lei de Diretrizes e Bases da Educação (LDB). Disponível em: $<$ http://www.educacao.ba.gov.br>. Acesso em: out. de 2016.

Recebido em 12 de novembro de 2016.

Aceito em 1 de dezembro de 2016. 